\title{
Georgia: Poverty Reduction Strategy Paper Progress Report- Joint Staff Advisory Note
}

The attached Joint Staff Advisory Note (JSAN) of the Poverty Reduction Strategy Paper Progress Report for Georgia, prepared jointly by the staffs of the World Bank and the IMF, was distributed with the member country's Poverty Reduction Strategy Paper Progress Report to the Executive Boards of the two institutions. The objective of the JSAN is to provide focused, frank, and constructive feedback to the country on progress in implementing its Poverty Reduction Strategy (PRS).

To assist the IMF in evaluating the publication policy, reader comments are invited and may be sent by e-mail to publicationpolicy@imf.org.

\author{
Copies of this report are available to the public from \\ International Monetary Fund • Publication Services \\ $70019^{\text {th }}$ Street, N.W. • Washington, D.C. 20431 \\ Telephone: (202) 623-7430 • Telefax: (202) 623-7201 \\ E-mail: publications@imf.org • Internet: http://www.imf.org
}

\section{International Monetary Fund Washington, D.C.}





\section{INTERNATIONAL DEVELOPMENT ASSOCIATION}

AND

INTERNATIONAL MONETARY FUND

GEORGIA

Joint Staff Advisory Note
on the Poverty Reduction Strategy Paper Progress Report

Prepared by the Staffs of the International Development Association (IDA)

and the International Monetary Fund (IMF)

Approved by Kathleen McCollom (IDA)

and David Owen and Adnan Mazarei (IMF)

September 25, 2006

\section{OVERVIEW}

1. The Poverty Reduction Strategy Paper Progress Report (PRSP Progress Report, of August 2006) confirms the commitment of the government to the PRSP objectives, describes key results of the implementation over the last 18 months, and highlights new dimensions in the strategy. The PRSP Progress Report, or Economic Development and Poverty Reduction Program Progress Report (EDPRP Progress Report) as it is known in Georgia, is the second Annual Progress Report (APR) on the poverty reduction strategy. This Joint Staff Advisory Note (JSAN) discusses the strategy's implementation to date, and provides the staffs' advice on key priorities for strengthening the EDPRP further.

2. Overall, the APR provides evidence of continued strong economic performance, as well as progress on structural reforms in $\mathbf{2 0 0 5}$ and the first half of 2006. GDP growth was 9.3 percent in 2005 but is expected to slow in 2006 to around 7.5 percent, partly as a result of external shocks. Inflation remained in single digits in 2005 but accelerated during 2006 reaching 14.5 percent as of end-July, before declining to 13.4 percent at end-August. As the government considers price stability a condition for sustained economic growth and poverty reduction, measures are under way to reduce inflationary pressures, including tightening the fiscal stance by targeting a deficit of 2.5 percent of GDP in 2006, and tightening the monetary stance by reducing the target 2006 growth rate of reserve money from 25 percent to 15 percent. 
3. The structural reform strategy is anchored on improving governance, reducing the burden of the state on the economy, and improving living standards. The results achieved so far in curbing corruption and improving the business climate are impressive and create the potential for broad based growth in the future, which should reduce unemployment and poverty over time. Building on these achievements, the challenge is to implement the new regulatory framework, develop the capacity to monitor and report on outcomes of the reforms, and translate progress into lasting institutional improvements.

\section{POVERTY Diagnosis}

\section{The government has significantly improved the statistical framework for} measuring poverty. The new methodology on poverty measurement, developed in close collaboration with World Bank staff, follows international standards and allows a more accurate and reliable measurement of poverty than the previous methodology.

5. Despite strong GDP growth, poverty increased during 2004-05, partly because unemployment continued to rise. In part because public sector reforms required the layoff of civil servants, unemployment increased from the already high pre-reform level and reached 13.8 percent in 2005. Together with weaknesses in the social assistance system, this contributed to an increase in the overall poverty incidence from 35.7 percent in 2004 to 39.4 percent in 2005 . Inequality rose slightly, as reflected in an increase in the Gini coefficient from 0.37 in 2004 to 0.39 in 2005 . While poverty declined in the first quarter of 2006 to 33.6 percent, a solid trend towards poverty reduction is yet to be established.

6. Timely implementation of the measures outlined in the APR for improving the effectiveness of Georgia's social assistance system is essential to reducing extreme poverty. The authorities recognize that, in addition to solid growth, poverty reduction requires an effective social assistance system. Despite delays, progress has been made: the APR reports that the medical insurance program for the extreme poor began to be implemented in July 2006. Similarly, the poverty benefit for the extreme poor was introduced in Tbilisi in August 2006 and was expanded nationwide in September. However, further progress is needed to enhance the social assistance system's effectiveness while ensuring its fiscal sustainability. In addition to addressing deficiencies due to fragmentation, the APR notes that the authorities also intend to improve the targeting of the poverty reduction program and to move from in-kind to financial benefits which will enhance the program's efficiency and effectiveness.

7. In order to build an effective poverty monitoring system, it is essential to create an independent, technically competent public statistical agency. The Department of Statistics should continue strengthening its technical capacities to allow a thorough monitoring of poverty trends. In particular, it is important to further improve the household survey and poverty measurement methodology. The staffs recommend making the Georgian Department of Statistics an independent institution, in line with best practices in the region. 


\section{Macroeconomic Policies ANd Framework}

8. The staffs of IDA and the IMF support the thrust of the macroeconomic policies proposed in the APR. While the report provides a comprehensive overview of macroeconomic developments in 2005, an analysis of the causes of the upswing in inflation during 2006 is missing. In view of the sharp increase of inflation during the first half of 2006, which in staffs' view was mainly driven by rapid money growth, it would have been useful to spell out how the government and NBG will limit money growth to non-inflationary levels.

\section{Looking forward, the report provides only limited information on the main} parameters of the macroeconomic framework. Besides the inflation target of 5-6 percent, the only medium-term macroeconomic targets explicitly mentioned are the international reserve coverage (equivalent to 2.5 months of imports) and GDP growth of 7.5 percent. In order to integrate the PRSP's tasks into the government's macroeconomic policies, it would have been useful to present a more comprehensive macroeconomic framework, including the country's external position, in view of the difficult relations with its main trading partner, uncertainties about future energy prices, and vulnerabilities arising from large private inflows. Future APR's could also analyze the impact of external vulnerabilities and political shocks in macroeconomic stress tests.

\section{While monetary policies in support of the inflation target are spelled out in} principle, the NBG's balancing act between stabilizing the exchange rate and controlling inflation could have been discussed in more detail. The report presents a strategy for conducting monetary policy and a comprehensive proposal for strengthening the institutional framework for the banking sector in the future. However, it would have been useful to explain in more detail how the NBG intends to balance the tasks of restraining inflation with appreciation pressures arising from private foreign inflows. During the first half of 2006, the focus of the NBG's interventions was less on controlling inflation than on limiting appreciation, which has negative income and wealth effects due to the high dollarization of savings and large remittances from abroad.

\section{Although the government prepared its first Medium-term Expenditure} Framework (MTEF) since the last PRSP, the PRSP is not integrated with the MTEF. The PRSP does not provide cost estimates for the government's planned new initiatives. Without these cost estimates which need to be integrated in the MTEF, it remains unclear how the government intends to fulfill its goals listed in the PRSP while preserving a sustainable fiscal position. In addition, staffs note that to improve the efficiency and effectiveness of public spending, the outcome of public programs needs to be assessed through performance indicators. 


\section{Public Expenditure Management}

12. Staffs encourage the authorities to make every effort to ensure a more systematic implementation of newly adopted public expenditure management systems and practices. The APR reports on several milestones in the progress toward a modern public expenditure management system, including advances toward program budgeting, a growing autonomy of spending units in defining policies and directions, the MTEF which is based on the comprehensive Basic Data and Directions 2007-2010, and the introduction of the Treasury Single Account. However, further reforms are necessary, including improved accountability and transparency of public spending. Staffs recommend that, in the short term, priority should be given to expanding fiscal and transparency rules to the Legal Entities of Public Law (LEPLs). In the medium term, efforts should focus on the following priorities:

- $\quad$ Strengthening medium-term budget planning by fully integrating the MTEF goals into the annual budget planning process;

- $\quad$ Developing a management structure for public investment;

- $\quad$ Move to international accounting standards based on GFS-2001.

Strengthening line ministries' capacity will be necessary for progress in these areas.

13. In order for the decentralization effort to succeed, capacity building at the local level should be accelerated. The APR reports on the decentralization reform which includes a consolidation of administrative units accompanied by delegating responsibilities, revenues, and autonomy. In 2005, the organic law on Local Self-Government was enacted which consolidates 1,000 local government units into 70 units with new administrative structures. In addition, the Law on Local Self-Government Budget was approved in the summer of 2006 which, for the first time, establishes a clearly defined formula-based equalization system for expenditure allocation. The latter also determines rules on the control, audit, evaluation and execution of local budgets. The APR notes that the authorities plan to start implementing the Law on Local Self-Government Budget with the 2007 budget. However, staffs note that major efforts are needed to develop local capacity at the local level.

\section{Sectoral Policies}

14. Significant advances in education reform provide a solid platform for improving implementation of per student funding and carrying through optimization plans. The APR reports on the substantial progress that has been made toward the three main goals of the first stage of the education system reform: (i) harmonizing the education system with European standards; (ii) eradicating corruption at all levels of the education system; and (iii) implementing a per-student financing system. The reforms aim at delegating responsibility to schools and institutions while increasing per capita financing at the general 
education level. In addition, Georgia has introduced transparent examinations for university admission and is participating in the Trends in International Mathematics and Science Study and in the Progress in International Reading Literacy Study which will for the first time allow a comparison of Georgia's education system with other countries. Important reforms need to be implemented over the medium term, including improving implementation of per student financing and optimization plans. In order to monitor performance in the education sector, performance indicators need to be introduced.

15. In the health sector, the APR rightly emphasizes the importance of revising the basic benefit package, while simultaneously addressing issues of primary health care needs, but the analysis of the fiscal implications of the reform could be strengthened. The APR highlights the importance placed by the government on the Basic Benefit Package (BBP) for the whole population and the Supplementary Benefit Package (SBP) for the poor, as well as on maternal and child health. The APR reports on the advances that have been achieved in the area of primary health care services, a core component of the BBP and provides details on investment needs in infrastructure for primary health care facilities and maternal and child health facilities, in particular. While staffs welcome the government's activities in the above-mentioned areas, they urge the government to identify investment needs in the hospital infrastructure and the financing requirements of the various packages. Also, future APRs should provide information on health related indicators included in the 2003 PRSP, such as infant and under-five mortality rates and advances on HIV/AIDS and other major diseases.

16. The APR reflects continued improvements in the energy sector. Except for an interruption of energy supplies from abroad in January 2006, customers largely received 24 hours' power supply through the winter of 2005/06. This constitutes a substantial improvement over earlier years. Financial flows were much improved through progress in collections, while investments contributed to technical improvements. Financial flows to domestic upstream service providers (power transmission and hydropower generation) are, however, still inadequate. The government introduced large tariff increases in June 2006 to address this problem and believes privatization will provide further financial discipline. To protect vulnerable groups in society, the government introduced a life line program. Staffs commend these efforts but note that tariff increases and privatization may not entirely solve the problems in the sector. To achieve and maintain adequate quality of service, it is important that competent regulation of power distribution service standards be implemented, requiring private operators to invest to meet such standards. The government and its remaining state-owned companies will have to develop financing solutions for the stillsubstantial investment needs in power and natural gas transmission and for developing domestic power production to improve Georgia's energy security.

17. Staffs welcome simplification of the regulatory and administrative frameworks in the transportation sector but note that important institutional challenges remain. On the regulatory framework, the APR reports on the successful liberalization of transport 
regulations, consolidation of three regulatory administrations into a unified institution, and the results of significantly increased spending on road rehabilitation and development. The new regulatory framework needs to be closely monitored and revised, as appropriate. Furthermore, the new institution needs to develop a monitoring and public reporting system. On the railway system, the government completed a technical assessment of the railways, including investment needs and options for restructuring, and the APR reports on investment programs and pilots already under discussion. As next steps, staffs recommend preparing a market demand analysis for rail transport and exploring private sector participation in railway operations. In motor transport, the APR reports that administrative transit procedures have been simplified, including through the abolition of the road tax and the reduction in the number of permits. However, the revised regulations should ensure the sustainability and safety in motor transport. On air traffic, progress has been made in liberalizing airport management; Tbilisi and Batumi airports have undergone reconstruction and are run by private management. Future reforms should focus on the civil aviation licensing law and on how Air Traffic Control, both regionally and at the airports, is organized, priced and financed. On maritime transport, progress has been made in involving the private sector through concession contracts for the management of Batumi and Poti ports.

18. In the road sector, significant increases in spending need to be accompanied by improved road management capacity, and the development of multi-year investment and maintenance plans. The APR reports on the significant improvement in the conditions of roads and bridges as a result of increased financing. However, priorities for future spending need to be determined on the basis of robust technical and economic criteria within a long term vision, and a plan for building local governments' capacity to maintain local roads should be developed prior to any further decentralization of road management.

19. The deregulation of the agricultural sector should be supplemented by a licensing and inspection process that meets international norms and WTO requirements while continuing to provide a safe environment for consumers. The APR reports on progress made on recent legal and institutional reforms to deregulate the agricultural sector while strengthening food safety measures. Implementation of the regulatory framework will require retraining of government monitoring and regulatory staff and effective engagement of private sector service providers, while agri-business management and the broader community will require training in modern sanitary and phytosanitary protection, food safety, and quality management. Further work is also needed on the irrigation and drainage sub-sector reform strategy. The APR also reports on efforts to encourage the development of rural credit unions and to strengthen the functioning of rural financing, which the staffs fully support.

20. The APR describes the progress in environmental protection but provides limited information on monitoring indicators. Staffs welcome the establishment of a governmental commission, aimed at a stronger coordination across public entities in implementing the strategy for sustainable development. Staffs commend the government for 
developing solid links between priorities, budget allocations and outcomes in the sectoral budget paper for the MTEF in 2005 and encourage the ministry to strengthen reporting of outcome indicators. While Georgia's policy and institutional framework for environmental protection compares well with its peers, implementation and enforcement should be strengthened.

\section{TRANSPARENCY AND ACCOUNTABILITY}

\section{Georgia's impressive progress in fighting corruption should be turned into} lasting institutional changes. The APR does not fully report on the wide range of bold actions taken by the authorities to curb corruption and improve the business climate, including notably the prosecution of high-profile former officials suspected of corruption, and the retrenchment in the civil service accompanied by a rise in remunerations. The latter has resulted in visible improvements in governance, including a sharp reduction in the extortion of bribes by the traffic police. The APR does report on various tax and customs reforms including the approval of a new tax code that significantly reduced the number of taxes, the reorganization and re-staffing of the tax and customs offices, and the adoption of a new law on financial amnesty which have been effective in limiting corruption. The EBRDWorld Bank Business Environment and Economic Performance Survey of 2005 shows Georgia had the largest improvement in curbing corruption in 2002-2005 among 27 countries in Europe and Central Asia. ${ }^{1}$ Staffs recommend that the next steps include a focus on implementing long lasting institutional changes and on improving the functioning of the judiciary.

\section{Similarly there has been substantial progress in improving the business climate.}

The APR reports that, in addition to adopting a new tax code, the regulatory and administrative framework for businesses has been greatly simplified and modernized in the areas of standardization, metrology, accreditation, and certification. The minimum capital requirement for limited liability companies has been reduced from 2,000 to 200 Lari. In addition, the new Law on Customs Tariffs, which became effective on September 1, reduced the number of tariff rates from 16 to 3 and has a very low average weighted tariff rate of 1.5 percent. Georgia recently adopted a new Labor Code, which is one of the most liberal in Europe and Central Asia. According to the World Bank's Doing Business 2007 indicators, these measures place Georgia as the number one reformer in the world. The staffs agree with the authorities that, to realize the benefit of these reforms, the next steps should focus on implementation.

23. While the increase in financial intermediation stimulates economic growth, the quality of commercial banks' lending portfolio needs to be closely monitored. The APR records rapid development of the banking sector. Credit to the private sector increased by around 80 percent in 2005, a pace that continued in the first half of 2006. Staffs note that

\footnotetext{
${ }^{1}$ See Anticorruption in Transition 3, 2006, the World Bank.
} 
these developments are not without risks and underline the urgency of implementing the NBG's structural reform agenda, in particular (i) upgrading banking supervisory policy; (ii) strengthening implementation of Basel Core Principles, particularly for the Fit and Proper Criteria for bank administrators and large shareholders; (iii) strengthening banking sector transparency; and (iv) continuing to close or merge commercial banks that do not comply with prudential regulations.

24. While the APR highlights progress in privatization, more detailed information would have been useful on the transparency and fairness of the process. More extensive advertising could have made the privatization more transparent. Staffs urge the authorities to manage and plan carefully the use of privatization receipts. The government should continue to use part of the proceeds to strengthen the weak international reserve position, while some money could be invested for capital projects whose selection should be guided by a transparent public investment plan.

\section{Participation, COORdination, AND Monitoring}

25. While the APR benefited from consultations with civil society, a more systematic approach would have been desirable. The authorities carried out extensive consultations in several areas including customs reform, reforms in education and decentralization. The authorities are encouraged to adopt a more systematic approach toward such consultations.

\section{The poverty reduction strategy has been an important vehicle for donor} coordination. The government consults regularly with donors, both bilaterally and in the context of the Donors Framework Group, which has been established in support of the preparation and monitoring of the PRSP. However, staffs note that there is scope for further improving donor coordination.

\section{Monitoring and reporting of the results of the implementation of the PRSP can} be strengthened. As mentioned above, the authorities made progress in adopting a modern methodology for measurement of poverty. Monitoring of macroeconomic goals will be facilitated by the decision to transfer the main responsibility for balance of payments statistics to the NBG. The credibility of the Georgian Statistics Department would be strengthened if it became an independent technical body. The authorities are also encouraged to accelerate their efforts to develop performance indicators in the context of the MTEF and to report regularly to the public about the performance.

\section{CONCLUSION}

28. In sum, the implementation of Georgia's poverty reduction strategy over the past 18 months has proceeded well, with impressive achievements in curbing corruption, improving the business climate, and continued improvement in public finances. In the coming years, the challenge is to maintain reform momentum and to 
translate recent achievements into lasting institutional change. Particular emphasis should be given to the following areas:

- $\quad$ Enhancing macroeconomic management: Conflicts between exchange rate and price stability should be resolved by a clear focus on inflation, limiting the NBG's foreign exchange interventions to smoothing short-term fluctuations. Improvements in the business climate should attract more foreign investment over the medium term and help reduce external vulnerabilities. In the interim, prudent fiscal policies should limit pressures on international reserves and keep external debt on a declining path.

- $\quad$ Implementing the new legislative framework: Georgia is in the midst of implementing major reforms in many areas. To fully realize the benefits of these reforms, the new legislation needs to be implemented effectively. Developing implementation capacity at different levels of government and across different public sector areas will require a more systematic approach to building an efficient and accountable public administration.

- $\quad$ Improving the effectiveness of public expenditure policies: The MTEF needs to be further developed and linked more closely with the Basic Data and Directions, the PRSP, and the annual budget and supplements. With public consumption growing rapidly thanks to strong tax collections, improving efficiency and effectiveness in the use of public resources has become a priority. This will require strengthening technical skills for the analysis of public investment projects and developing comprehensive performance indicators for public spending.

- $\quad$ Enhancing the efficiency of infrastructure spending: In meeting infrastructure needs, priority should be determined on the basis of robust technical and economic criteria within a long-term vision.

- $\quad$ Supplementing pro-growth policies with an effective social safety net: This will require reforms to address the fragmentation of the system and to enhance the targeting to ensure that resources reach those that need them the most.

- $\quad$ Broadening improvements in governance by judicial reform: Growth and investment require strengthening governance which will entail restructuring the legal and judicial system, ensuring its professional competency, and strengthening its independence.

- $\quad$ Fostering participation of civil society in all dimensions of the reform strategy. 